\title{
A case of giant fetal intracranial capillary hemangioma cured with propranolol
}

\author{
Sergio Cavalheiro, MD, PhD, ${ }^{1}$ Heloisa Galvão do Amaral Campos, MD, PhD, ${ }^{2}$ and \\ Marcos Devanir Silva da Costa, MD, MSc ${ }^{1}$
}

\begin{abstract}
1Department of Neurosurgery, Federal University of São Paulo; and 'Department of Plastic Surgery, Hospital A.C. Camargo, São Paulo, São Paulo, Brazil
\end{abstract}

\begin{abstract}
Fetal brain tumors are rare. This report describes a giant posterior fossa capillary hemangioma treated with $3 \mathrm{mg} / \mathrm{kg} / \mathrm{day}$ of propranolol for 6 months. Total regression was confirmed at 1 year, and no additional tumors were observed during the subsequent 2 years. No side effects relating to the use of this drug were detected; thus, the authors believe that propranolol may be useful for treating all intracranial capillary hemangiomas.

http://thejns.org/doi/abs/10.3171/2015.11.PEDS15469
\end{abstract}

KEY WORDS capillary hemangioma; propranolol; fetal brain tumor; posterior fossa tumor; hydrocephalus; apoptosis; vascular disorders

$\mathrm{C}$ APILLARY hemangiomas are common benign vascular tumors in infants who often present with skin lesions on the face, neck, and thorax. ${ }^{6}$ Their occurrence in the central nervous system is a rare and challenging phenomenon because of their initial proliferative phase, which causes enlargement of the lesion, with a growth peak at 6 months after birth and the theoretical possibility of spontaneous regression. ${ }^{5,6}$ This regression is typically observed at 4 years of age (30\% of patients) and 7 years of age (80\% of patients). ${ }^{11}$ In our literature search, only case reports and small case series on intracranial capillary hemangiomas were found, and no uniform treatment was administered in the described cases. Surgery was performed in certain cases, whereas other cases involved clinical observation and/or treatment with steroids, thalidomide, bevacizumab, and/or temozolomide. $3,4,13,25$

A different scenario is applicable for cutaneous hemangiomas. ${ }^{12,15,24}$ In particular, for such tumors, propranolol has been the first-line treatment since Léauté-Labrèze et al. ${ }^{10}$ published a case series in 2008 that described severe infantile hemangiomas treated with this beta-blocker with excellent outcomes. To date, propranolol has not been described as a treatment for intracranial capillary hemangiomas. In this paper, we describe the first case in which an intracranial fetal capillary hemangioma has been successfully treated with propranolol.

\section{Case Report}

History and Examination

A healthy 24-year-old pregnant woman at 35 weeks of her first gestation underwent routine obstetrical ultrasonography (US) that demonstrated good fetal status but a bulky posterior fossa fetal tumor without hydrocephalus. At the 37th gestational week, a male child was delivered by cesarean section. The infant weighed $3030 \mathrm{~g}$ and exhibited 

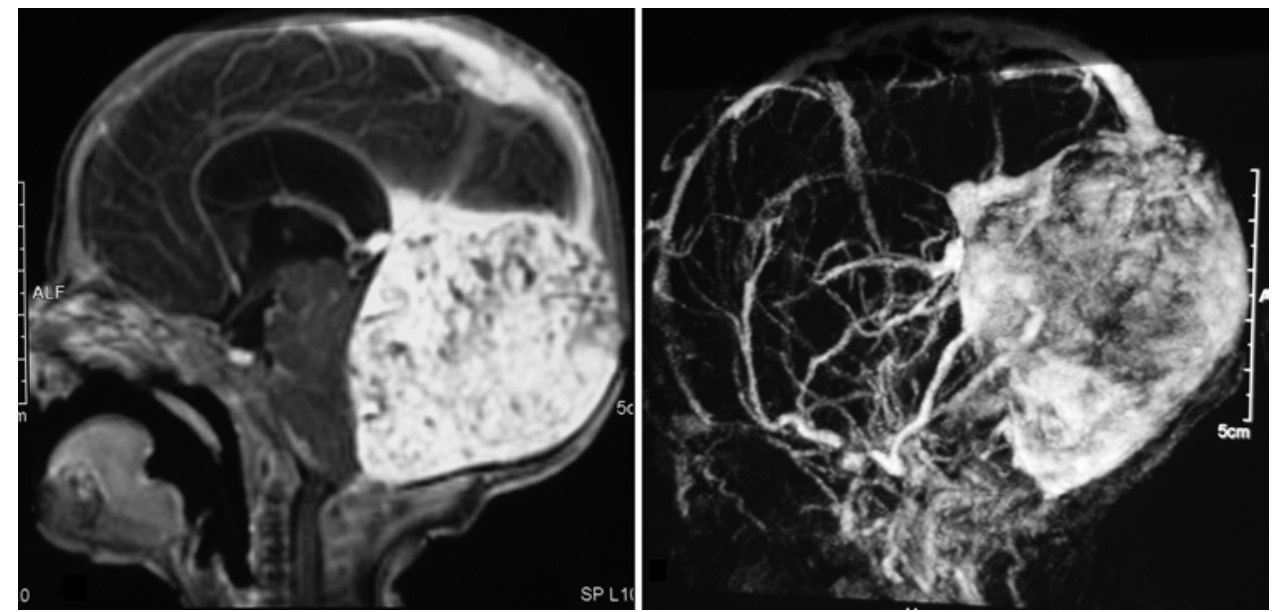

FIG. 1. Postnatal T1-weighted MR image after a Gd injection. Left: Sagittal view of the tumor, revealing the voluminous mass anteriorly displacing the brainstem. Right: Magnetic resonance angiogram indicating the highly vascular capillary lesion.

Apgar scores of 9 and 10 at 1 and 5 minutes, respectively, a head circumference of $36 \mathrm{~cm}$, and a slightly tense anterior fontanel. Neonatal transfontanellar US demonstrated the presence of a giant, homogeneous, hyperechogenic tumor in the posterior fossa that was causing anterior displacement of the brainstem and cerebellum, disjunction of the posterior fossa sutures, and hydrocephalus. A Doppler US evaluation indicated that the lesion was highly vascular and exhibited a low resistance index. Magnetic resonance imaging (MRI) revealed a large, homogeneous, Gd-enhancing lesion in the posterior fossa that was compressing the brainstem and cerebellum and appeared isointense with flow voids on T1-weighted sequences and hypointense on T2-weighted sequences (Fig. 1). Hypersignals were absent on diffusion-weighted sequences, and rich vascularity was revealed by angio-MRI.

Because of anterior brainstem displacement, intracranial pressure was relieved by placing a ventriculoperitoneal shunt in front of the large, hypervascular, life-threatening tumor in the posterior fossa that was causing hydrocephalus instead of performing an endoscopic third ventriculostomy (ETV). A Codman Hakim programmable shunt device (Codman \& Shurtleff Inc.) with an aperture pressure of $5 \mathrm{~mm} \mathrm{Hg}$ was used. At this time, we presumed that the tumor was an intracranial capillary hemangioma given its intense vascularization, and we therefore proceeded with propranolol treatment.

\section{Propranolol Treatment and Clinical Course}

We administered $3 \mathrm{mg} / \mathrm{kg} /$ day of propranolol every 12 hours for 6 months and monitored the infant's heart rate and arterial blood pressure, intensively at the beginning of treatment and then once a month. Imaging follow-up included US studies in the 2nd month after starting treatment and MRI examinations every 6 months. Follow-up US demonstrated partial reduction of the lesion. The first MRI examination, which was conducted during the 6th month after treatment initiation, indicated a $50 \%$ reduction in the lesion. At 1 year posttreatment, total regression of the tumor was observed. Two-year MRI confirmed total regression of the lesion (Fig. 2). The patient exhibited normal neuromotor development, and no adverse effects of beta-blocker use were observed.

\section{Discussion}

On patient admission in the described case, we considered a teratoid/rhabdoid tumor or a medulloblastoma as possible etiologies. However, fetal tumors are rare in the posterior fossa and are generally associated with high mortality rates; ${ }^{1}$ moreover, these tumors lack the high vascularity observed in this case. Given the intense vascu-

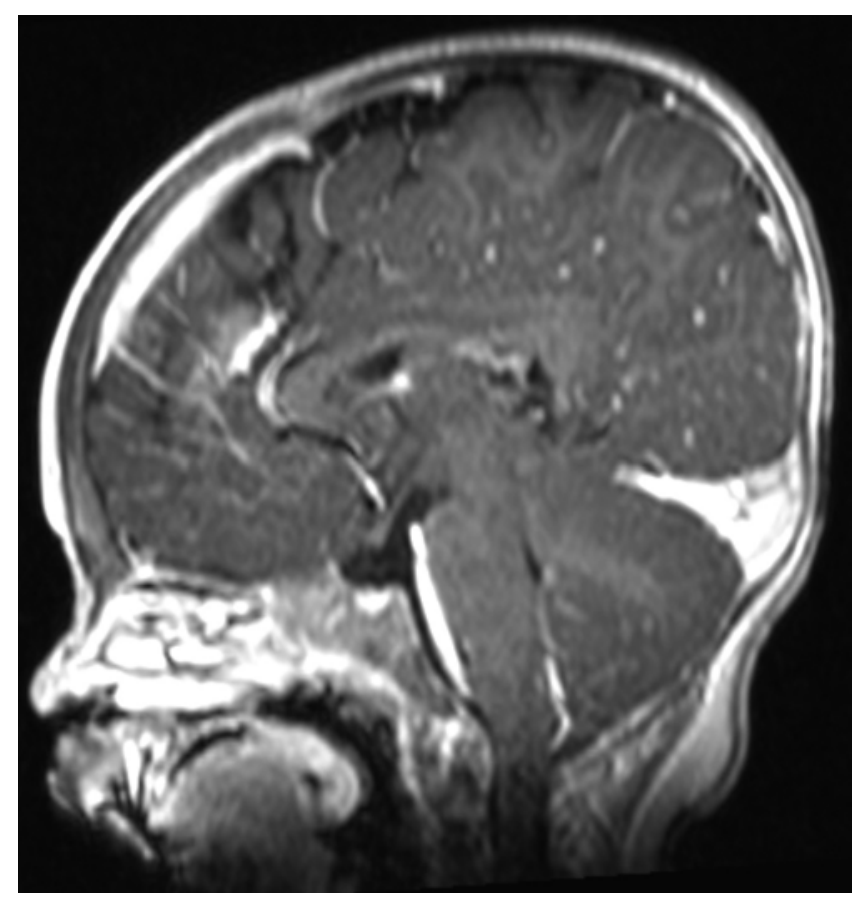

FIG. 2. Sagittal MR image obtained at the 2-year follow-up, demonstrating total regression of the lesion and release of the brainstem from tumor-related compression. 
larization of the tumor, a simple stereotactic biopsy could have led to a catastrophic hemorrhage. Thus, the patient was treated without pathological confirmation. In-depth analyses of the radiological findings, including high vascularity, excluded a teratoid/rhabdoid tumor and a medulloblastoma and suggested the possibility of a capillary hemangioma, which is a highly vascular lesion that is rare in the intracranial compartment but extremely common in the skin.

Capillary hemangiomas - also known as infantile hemangiomas, strawberry birthmarks, or hemangiomas - are benign vascular tumors characterized by an encapsulated mass that is lobular in shape with a poorly defined capillary channel consisting of a single layer of flattened endothelium without intervening brain parenchyma. ${ }^{8,9,11,14}$ These tumors typically affect the skin and the soft tissues of the face, scalp, back, or chest in children, ${ }^{2,6,8,14}$ appearing as a single lesion in $80 \%$ of cases. ${ }^{9,11}$ Their reported frequency in neonates ranges from $0.05 \%$ to $5 \% .{ }^{8,11}$ Although superficial hemangiomas are common, intracranial capillary hemangiomas are rare, and few cases of definite, probable, or possible ${ }^{16}$ congenital intracranial capillary hemangiomas have been described in the literature; published cases are listed in Table $1 .^{2,3,6-9,21-23}$

Intracranial capillary hemangiomas can present as asymptomatic lesions or result in cranial nerve palsy, head circumference enlargement, and elevated intracranial pressure. In addition, these lesions are frequently associated with skin hemangiomas. Only 5 of 22 reviewed cases of intracranial capillary hemangiomas did not involve an associated skin hemangioma. Moreover, intracranial hemangiomas appear to be associated with PHACE syndrome $^{7,23}$ and exhibit a female predominance (with a male/female ratio of 1:2). ${ }^{8,11}$ Capillary hemangiomas are also characterized by a proliferative phase during the 1st months of life that is followed by spontaneous regression in most cases. ${ }^{5,18}$

Intracranial capillary hemangiomas are characterized by isointensity or hypointensity on T1-weighted MR images, with avid uniform contrast enhancement, and by hyperintensity on T2-weighted MR images. Because capillary hemangiomas present sinusoidal vascularization, the repetition of T1-weighted MRI at a different time with Gd could show a progressive enhancement differing from that observed with other posterior fossa tumors, which do not maintain this enhancement over time. On CT scans, these tumors are characterized by isodensity to hyperdensity, a lobulated morphology, and intense contrast enhancement. Although angiography is rarely performed, such studies of these tumors reveal enlarged arterial feeders and intense contrast staining, with pooling of the contrast medium

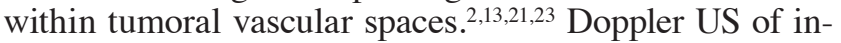
tracranial capillary hemangiomas indicates numerous intralesional and perilesional vessels, with a high-peak arterial Doppler shift. ${ }^{23}$ The aforementioned imaging findings are not exclusive to intracranial capillary hemangiomas; in fact, these tumors must primarily be differentiated from meningiomas, hemangiopericytomas, and hemangioblastomas.

To date, as indicated in Table 1, no consensus exists regarding the treatment of intracranial capillary hemangio- mas. In particular, the various therapies for these tumors include surgical removal, systemic steroid therapy, thalidomide, intralesional triamcinolone, bevacizumab, temozolomide, interferon, and clinical observation. . $^{2,3,6-9,21-23,25}$ The same variations in treatment were observed for capillary hemangiomas in the skin until 2008, when LéautéLabrèze et al..$^{10}$ described 11 patients with complicated infantile hemangiomas who were treated with propranolol and exhibited dramatic lesion regression within a short time period with minimal adverse effects. Subsequently, many authors began to examine propranolol and its role in capillary hemangioma treatment and have suggested this beta-blocker as a first-line treatment for severe infantile capillary hemangiomas..$^{12,15,24}$

Propranolol is a nonselective beta-adrenergic receptor antagonist that appears to promote vasoconstriction in capillary hemangiomas, reducing blood flow within these lesions and causing skin capillary hemangiomas to change color and soften. This beta-blocker appears to inhibit angiogenesis by decreasing the expression of proangiogenic growth factors, such as vascular endothelial growth factor (VEGF) and basic fibroblast growth factor (bFGF), most likely by inactivating the extracellular signal-related kinase/mitogen-activated protein kinase (ERK/MAPK) cascade. Another potential underlying mechanism of propranolol's antiangiogenic effects is its reduction of matrix metalloproteinase-9 (MMP-9) expression, which leads to the inhibition of endothelial cell tubulogenesis. ${ }^{18,20}$ Moreover, propranolol promotes the induction of apoptosis in capillary endothelial cells by blocking apoptosis inhibition by beta-adrenergic agonists (mediated by MAPK and the caspase cascade) and thereby increasing apoptosis rates. ${ }^{17,18}$

Ghosh and Ghosh ${ }^{4}$ reported the use of propranolol in a 6-week-old female infant with cutaneous and intraspinal-extradural capillary hemangiomas, who exhibited an excellent response. Strahle et al. ${ }^{19}$ suggested the theoretical possibility of using propranolol to treat intracranial capillary hemangiomas based on the evident success of propranolol treatment for skin lesions and the occurrence of fewer adverse effects from propranolol treatment relative to steroid, thalidomide, bevacizumab, and temozolomide therapies. The most frequent side effects of propranolol use are low blood pressure, bradycardia, bronchospasm, and hypoglycemia. Although capillary hemangiomas can spontaneously regress, when the tumor mass compresses brain tissue (such as in the brainstem, as detailed in the described case), treatment must be provided to relieve this compression because spontaneous total regression could take a long time. Surgical removal can be life-threatening given the intense vascularization of these tumors as well as a patient's low weight and young age. Given this consideration and the knowledge that propranolol could cause the regression of capillary hemangiomas during the proliferative phase, we began to administer propranolol to a neonate with a giant, life-threatening intracranial capillary hemangioma. Our treatment produced subtotal regression by the 6-month follow-up and total regression by the 1-year follow-up, and the treated patient exhibited normal cognitive and motor development. 


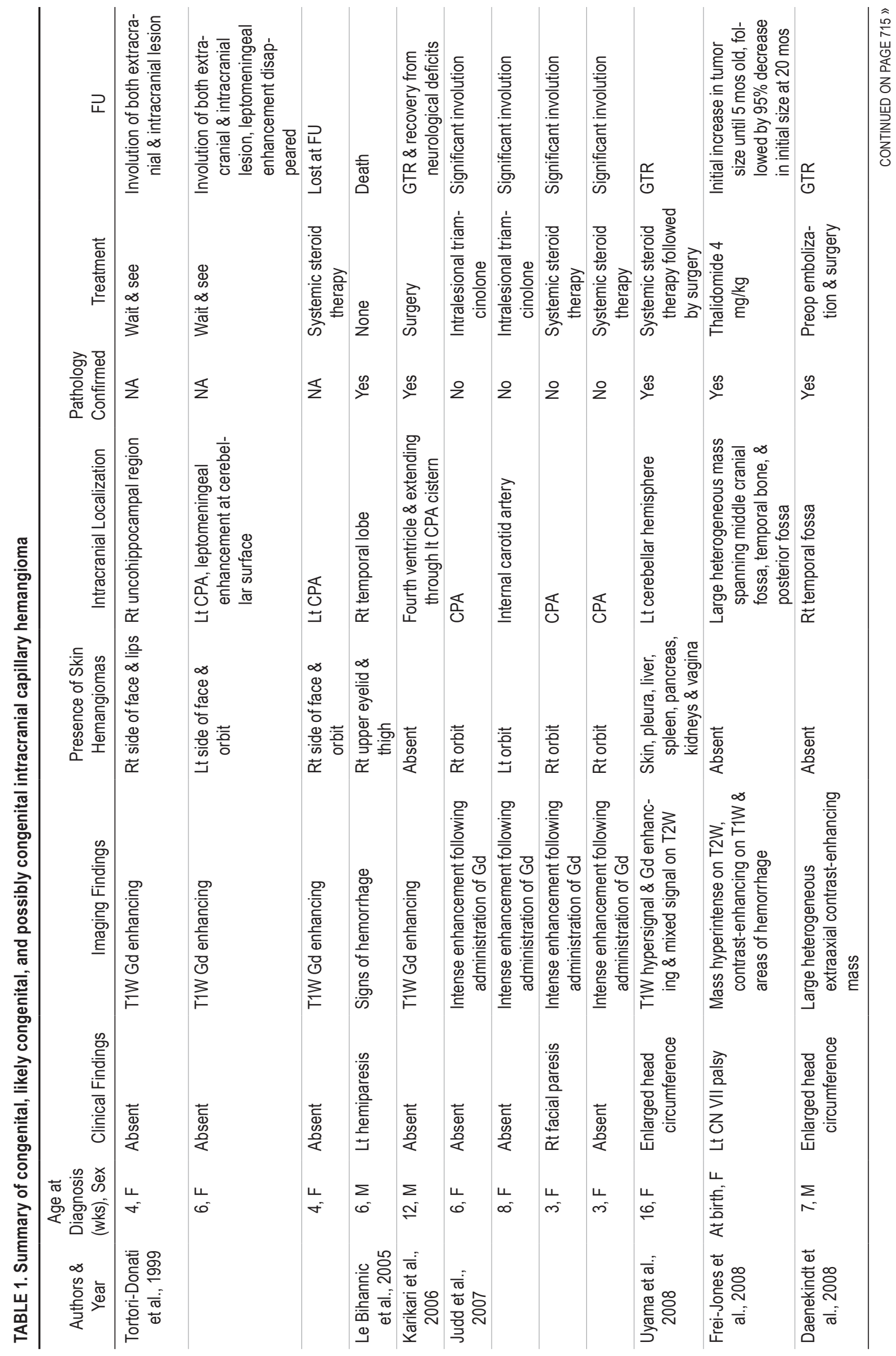




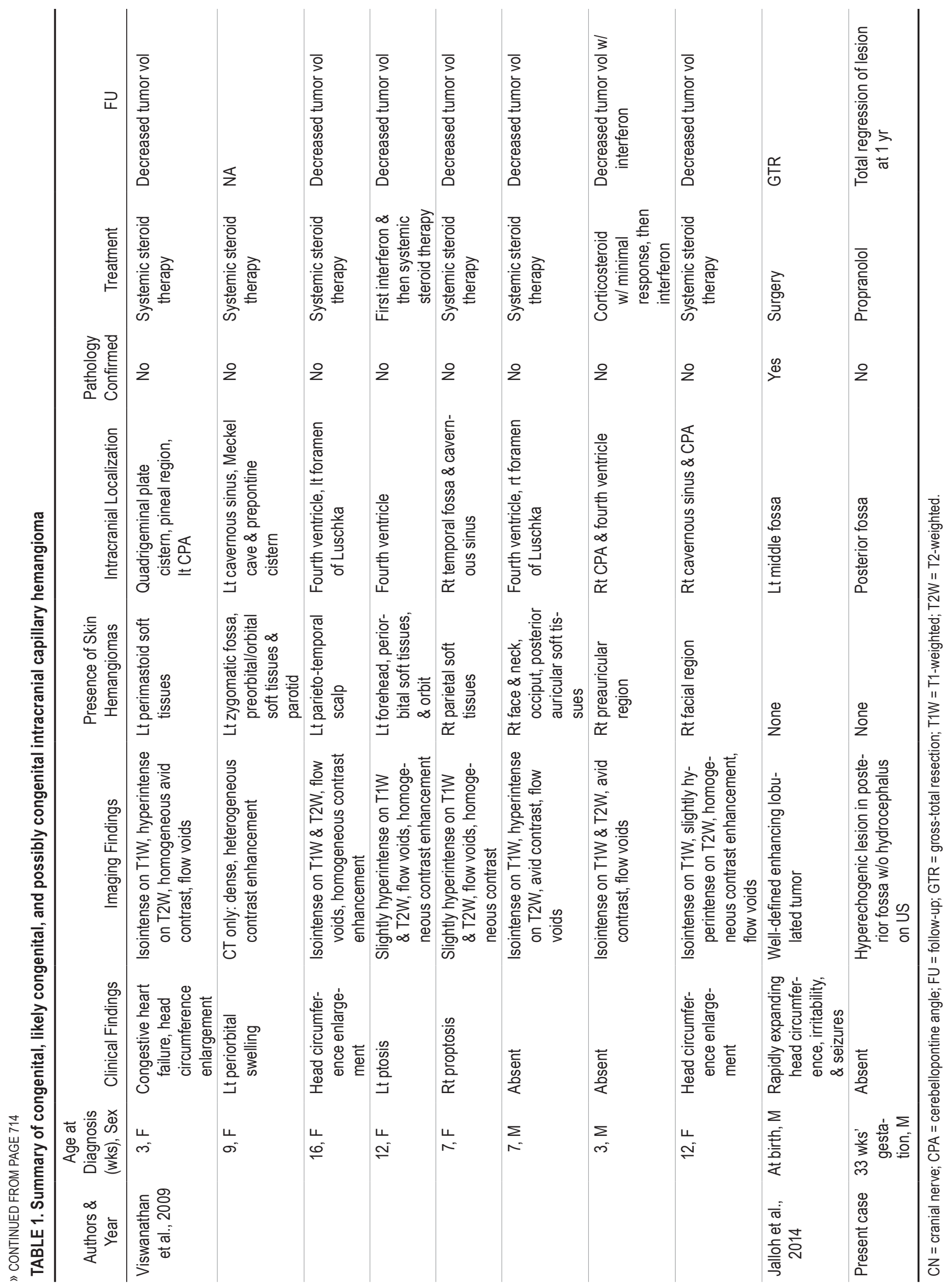




\section{References}

1. Cavalheiro S, Moron AF, Hisaba W, Dastoli P, Silva NS: Fetal brain tumors. Childs Nerv Syst 19:529-536, 2003

2. Daenekindt T, Weyns F, Kho KH, Peuskens D, Engelborghs $\mathrm{K}$, Wuyts J: Giant intracranial capillary hemangioma associated with enlarged head circumference in a newborn. J Neurosurg Pediatr 1:488-492, 2008

3. Frei-Jones M, McKinstry RC, Perry A, Leonard JR, Park TS, Rubin JB: Use of thalidomide to diminish growth velocity in a life-threatening congenital intracranial hemangioma. J Neurosurg Pediatr 2:125-129, 2008

4. Ghosh PS, Ghosh D: Infantile intraspinal and extensive cutaneous hemangiomas: excellent response to propranolol. Neurology 76:1771, 2011

5. Hamlat A, Adn M, Pasqualini E, Brassier G, Askar B: Pathophysiology of capillary haemangioma growth after birth. Med Hypotheses 64:1093-1096, 2005

6. Jalloh I, Dean AF, O'Donovan DG, Cross J, Garnett MR, Santarius T: Giant intracranial hemangioma in a neonate. Acta Neurochir (Wien) 156:1151-1154, 2014

7. Judd CD, Chapman PR, Koch B, Shea CJ: Intracranial infantile hemangiomas associated with PHACE syndrome. AJNR Am J Neuroradiol 28:25-29, 2007

8. Karikari IO, Selznick LA, Cummings TJ, George TM: Capillary hemangioma of the fourth ventricle in an infant. Case report and review of the literature. J Neurosurg 104 (3 Suppl):188-191, 2006

9. Le Bihannic A, Michot C, Heckly A, Loget P, Beucher A, Brassier G, et al: Capillary haemangioma arising from the anterior choroidal artery. Childs Nerv Syst 21:265-271, 2005

10. Léauté-Labrèze C, Dumas de la Roque E, Hubiche T, Boralevi F, Thambo JB, Taïeb A: Propranolol for severe hemangiomas of infancy. N Engl J Med 358:2649-2651, 2008

11. Leonardi-Bee J, Batta K, O'Brien C, Bath-Hextall FJ: Interventions for infantile haemangiomas (strawberry birthmarks) of the skin. Cochrane Database Syst Rev (5):CD006545, 2011

12. Lou Y, Peng WJ, Cao Y, Cao DS, Xie J, Li HH: The effectiveness of propranolol in treating infantile haemangiomas: a meta-analysis including 35 studies. Br J Clin Pharmacol 78:44-57, 2014

13. Mirza B, Shi WY, Phadke R, Holton JL, Turner C, Plant GT, et al: Strawberries on the brain-intracranial capillary hemangioma: two case reports and systematic literature review in children and adults. World Neurosurg 80:900.e13-900.e21, 2013

14. Morace R, Marongiu A, Vangelista T, Galasso V, Colonnese C, Giangaspero F, et al: Intracranial capillary hemangioma: a description of four cases. World Neurosurg 78:191.E15-191. E21, 2012

15. Sans V, de la Roque ED, Berge J, Grenier N, Boralevi F, Mazereeuw-Hautier J, et al: Propranolol for severe infantile hemangiomas: follow-up report. Pediatrics 124:e423-e431, 2009
16. Severino M, Schwartz ES, Thurnher MM, Rydland J, Nikas I, Rossi A: Congenital tumors of the central nervous system. Neuroradiology 52:531-548, 2010

17. Sommers Smith SK, Smith DM: Beta blockade induces apoptosis in cultured capillary endothelial cells. In Vitro Cell Dev Biol Anim 38:298-304, 2002

18. Storch $\mathrm{CH}$, Hoeger PH: Propranolol for infantile haemangiomas: insights into the molecular mechanisms of action. Br J Dermatol 163:269-274, 2010

19. Strahle J, Odden AJ, Maher CO, Garton HJ: Hemangiomas and propranolol. J Neurosurg Pediatr 12:418, 2013 (Letter)

20. Thaivalappil S, Bauman N, Saieg A, Movius E, Brown KJ, Preciado D: Propranolol-mediated attenuation of MMP-9 excretion in infants with hemangiomas. JAMA Otolaryngol Head Neck Surg 139:1026-1031, 2013

21. Tortori-Donati P, Fondelli MP, Rossi A, Bava GL: Intracranial contrast-enhancing masses in infants with capillary haemangioma of the head and neck: intracranial capillary haemangioma? Neuroradiology 41:369-375, 1999

22. Uyama A, Kawamura A, Akiyama H, Nakamizo S, Yamamoto K, Nagashima T, et al: A case of cerebellar capillary hemangioma with multiple cysts. Pediatr Neurosurg 44:344-349, 2008

23. Viswanathan V, Smith ER, Mulliken JB, Fishman SJ, Kozakewich HP, Burrows PE, et al: Infantile hemangiomas involving the neuraxis: clinical and imaging findings. AJNR Am J Neuroradiol 30:1005-1013, 2009

24. Xu S, Jia R, Ge S, Lin M, Fan X: Treatment of periorbital infantile haemangiomas: a systematic literature review on propranolol or steroids. J Paediatr Child Health 50:271-279, 2014

25. Yeo KK, Puscasiu E, Keating RF, Rood BR: Durable response of intracranial cellular hemangioma to bevacizumab and temozolomide. J Neurosurg Pediatr 11:682-686, 2013

\section{Disclosures}

The authors report no conflict of interest concerning the materials or methods used in this study or the findings specified in this paper.

\section{Author Contributions}

Conception and design: Cavalheiro, Costa. Acquisition of data: Cavalheiro, Costa. Analysis and interpretation of data: all authors. Drafting the article: Cavalheiro, Costa. Critically revising the article: all authors. Reviewed submitted version of manuscript: all authors. Approved the final version of the manuscript on behalf of all authors: Cavalheiro. Administrative/technical/material support: Cavalheiro.

\section{Correspondence}

Sergio Cavalheiro, Department of Neurosurgery, Federal University of São Paulo, Rua Botucatu, 591, conj 41, São Paulo 04023062, Brazil. email: sergiocavalheironeuro@gmail.com. 